Article

\title{
Performance Bonuses and Effort: Evidence from Fight Night Awards in Mixed Martial Arts
}

\author{
Paul Gift \\ Pepperdine Graziadio Business School, Los Angeles, CA 90045, USA; paul.gift@pepperdine.edu
}

Received: 12 January 2019; Accepted: 10 February 2019; Published: 20 February 2019

\begin{abstract}
This paper investigates the role of fight night bonus awards on fighter behavior in the Ultimate Fighting Championship (UFC) and World Extreme Cage (WEC) fighting mixed martial arts (MMA) promotions. Behavior is analyzed using detailed fighter performance statistics, exploiting variation in bonus size across events and over time. Findings suggest that fighters are not meaningfully influenced by bonus levels within the range observed in the sample period and possible explanations are discussed. Fight night bonuses appear to serve as a lottery compensation mechanism to ex post reward performances consistent with an MMA promotion's desires rather than ex ante incentivize such performances. Findings have implications for strategic MMA promoter decisions and contribute more broadly to the personnel economics literature on incentives and compensation.
\end{abstract}

Keywords: bonuses; effort; fighter performance; mixed martial arts (MMA); Ultimate Fighting Championship (UFC); World Extreme Cagefighting (WEC); Zuffa LLC

JEL Classification: J33; M52; Z22

\section{Introduction}

A tournament occurs when economic agents compete for rewards on the basis of relative rank. The non-linear compensation structure of tournament rewards is designed to induce optimal effort levels and tournament theory predicts that more effort will be put into production when there is a large difference between winning and losing payouts (Lazear and Oyer 2012). Sports contests can be an ideal laboratory to test aspects of tournament theory, such as the incentive effects of bonuses or various compensation structures, as athlete performance is typically rigorously tracked, monetary incentives well documented, and the goal of production (winning, scoring, defending, etc.) is also generally well defined.

Much of the existing sports economics literature on monetary incentives and performance comes from less frequently examined sports. Ehrenberg and Bognanno (1990a, 1990b) analyze performance and prize money data from the PGA tour and find that larger total money prizes and marginal returns to effort in the final round each lead to lower golfer scores. Becker and Huselid (1992) examine two car-racing panels (NASCAR and IMSA) and find that larger tournament spreads have a positive impact on performance, and drivers undertake more risky behavior as the spread increases. In foot racing, Maloney and McCormick (2000) find that larger average prize sizes and prize spreads lead to lower race times. Lynch and Zax (2000) also study foot racing and appear to find evidence supporting the incentive effects of larger prize spreads. However, once controls for runner ability are included, most of their significant effects disappear. They argue that race times appeared faster with larger prizes because they attracted faster runners.

In mixed martial arts (MMA), much of the literature has examined the determinants of pay-per-view (PPV) demand or event attendance (Tainsky et al. 2012; Watanabe 2012; Tainsky et al. 2013; Watanabe 2015; Reams and Shapiro 2017), while Collier et al. (2012) and Gift (2018) analyzed MMA 
judges with Gift finding that judges tend to show favoritism towards larger betting favorites, those with insurmountable leads, and the fighter who won the previous round. Finally, in boxing, where fighter compensation is contracted in advance and performance and win bonuses are not utilized, Tenorio (2000) found suggestive evidence, through examination of successful title defenses, to argue for a moral hazard in effort exertion.

The present paper examines the incentive effects of fight night bonus awards in MMA. The sport of MMA is an intriguing non-experimental laboratory to examine bonus incentives because fighter performance statistics are meticulously and rigorously tracked by a statistical agency, FightMetric LLC, and fight night bonuses can be substantial, often 300 percent or more of a fighter's guaranteed show money compensation. During the sample period of the present study, bonuses were typically awarded following the conclusion of each event for Fight of the Night (FOTN), Knockout of the Night (KOTN), and Submission of the Night (SOTN). FOTN was awarded to "each of the fighters in the best fight of the night" (Ultimate Fighting Championship (UFC) 2014). Precise definitions of KOTN and SOTN were not made explicit but presumably were awarded to the fighters with the best knockout/technical knockout $(\mathrm{KO} / \mathrm{TKO})$ and submission finishes of the night, respectively. ${ }^{1}$

MMA bonuses essentially define a tournament-within-a-tournament compensation structure. Competition within an MMA promotion over time can be considered one long, continuous rank-order tournament. The current "winner" is the champion of each weight class and there is a constant stream of challengers. Consistent with tournament theory, there is a large disparity in the pay of highly-ranked fighters relative to their low-ranked counterparts. Champions and top-tier fighters can earn hundreds of thousands or even millions of dollars per fight while newly-signed fighters earned as little as $\$ 2000$ to show and $\$ 2000$ to win as recently as 2006 , increasing to $\$ 8000$ to show/win by the end of the sample period.

Within the continuous tournament for rankings and champion status in each weight class is a separate tournament that takes place within each event-a tournament for bonus awards. Thus, there can be conflicting incentives between exerting effort towards winning the fight and exerting effort towards obtaining a bonus, possibly to the detriment of winning.

In the remainder of the paper, I examine the effect of changes in monetary rewards on observable performance outcomes such as fight finishes, action, and positioning. I find no evidence that fighters are meaningfully influenced by bonus levels within the observed range and argue this is likely due to auxiliary incentives such as the non-linear compensation structure as fighters progress up the rankings, the potential effect of win bonuses, and the critical importance of winning for maintaining a roster spot in elite MMA.

\section{MMA/UFC Background}

Television critic Howard Rosenberg is credited with the first documented use of the term "mixed martial arts" (U.S. House of Representatives Committee on Energy and Commerce 2017) after UFC 1 matched a variety of martial arts styles against each other in a no-holds-barred competition. ${ }^{2}$ MMA has since become a legalized ${ }^{3}$ and regulated combat sport involving striking and grappling in standing positions or on the ground. MMA bouts may be held in either a ring or cage enclosure, but all bouts in the present study took place in an octagon-shaped cage.

In early 2001, Zuffa LLC purchased the UFC and soon grew into the largest MMA promotion and live PPV event provider in the world (UFC 2019). In December 2006, Zuffa purchased rival promoter World Extreme Cage (WEC) fighting and quickly transitioned the new acquisition to lighter weight divisions. Zuffa did not use the WEC as a feeder to the UFC, but rather an extension of the UFC into

1 FightMetric does not separately record whether a fight ended by knockout (KO) or technical knockout (TKO), so they will collectively be referred to as $\mathrm{KO} / \mathrm{TKO}$ for the remainder of the paper.

2 There were only two fouls at UFC 1: Eye gouging and biting. By 2017, there were 26 fouls under the Unified Rules of MMA.

3 In the U.S., MMA is now legal in all 50 states following New York's legalization of the sport in 2016 (Bieler 2016). 
the lower weight classes. Eighty percent of Zuffa's bouts with the WEC took place in the lightweight, featherweight, and bantamweight divisions. The dataset for this paper encompasses UFC and WEC events during the times they were owned by Zuffa and operated using the Unified Rules of MMA.

Bonuses were not part of the fighter pay structure in the early days of the UFC and Zuffa's ownership. Fighters received their contracted show money (and win money should they be victorious) as well as possible side-letter payments, PPV points, and any discretionary "locker room" bonuses the promotion decided to pay the fighter.

The first fight night bonus award was given at UFC Fight Night 3 on 16 January 2006. Throughout that year, most, but not all, events included fight night bonuses. Since UFC 66 on 30 December 2006, every UFC event has included such performance bonuses. The amount of the awards varied over time until March 2013 when the UFC standardized its bonuses at \$50,000 for all future events (MMA Junkie Staff 2013). ${ }^{4}$ The WEC offered performance bonuses for every event in the sample from January 2007 through December 2010. Its bonuses were typically smaller than those of the UFC. In December 2010, the WEC was shuttered and its fighters were absorbed into the UFC and its higher bonus structure.

Two long-time UFC fighters confirmed in private interviews that bonus amounts were communicated to all fighters during the pre-fight meeting on the day of weigh-ins. ${ }^{5}$ Thus, it appears fighters are ex ante aware of the monetary prize they will receive should they win a fight night award.

Following UFC 169 in February 2014, the UFC substituted two Performance of the Night (POTN) bonuses for KOTN and SOTN, partially to provide more flexibility in rewarding top fight finishes. If an event had no submissions, SOTN could not be awarded (likewise for KOTN), but there may have been two deserving $\mathrm{KO} / \mathrm{TKO}$ finishes. POTN provides a more flexible mechanism to reward desired fight finishes no matter the type: $\mathrm{KO} / \mathrm{TKO}$ or submission. However, from a research perspective it may influence the incentive mechanism examined in this paper. Thus, the sample period of the present study ends at UFC 169 on 1 February 2014, the final UFC event with KOTN and SOTN awards.

\section{Data}

The dataset for the present study encompasses the Zuffa-owned and operated UFC and WEC promotions from 4 May 2001-when the Unified Rules of MMA were first implemented in the UFC—-through 1 February 2014. Data on fight night bonuses were collected using publicly-available reports from major MMA media outlets such as MMA Fighting and MMA Junkie.

\subsection{FightMetric LLC}

Fighter performance statistics were obtained from FightMetric for all UFC and WEC events promoted under the Zuffa banner from UFC 31 on 4 May 2001 through UFC 169 on 1 February $2014 .^{6}$ For each bout, FightMetric tracks over 100 fighter performance statistics covering striking, knockdowns, takedowns, grappling, submissions, and time spent in different positions. The statistics are documented and verified using frame-by-frame analysis of the bout video, if need be (Genauer 2013).

For the purposes of the present study, FightMetric does not distinguish between punches, kicks, knees, and elbows. They are all classified as "strikes" with their type being "jab" or "power." A jab is a non-power strike and FightMetric uses physical cues to determine if a strike has power or not. Submissions include chokes, where blood is cut off to the brain or breathing impaired, and joint locks, where pressure is applied to large joints such as elbows, shoulders, wrists, ankles, or knees in a manner in which they are not intended to bend. FightMetric also tracks the amount of time each fighter spends

4 There were four exceptions to the UFC's standardized bonus policy through the end of the sample period in February 2014 resulting in bonuses of $\$ 60,000$ (twice), $\$ 65,000$, and $\$ 75,000$. In one case, a fighter reportedly convinced UFC President Dana White to increase the bonus to $\$ 65,000$ during the pre-fight meeting, which suggests fighters are cognizant of bonus sizes leading up to an event (Marrocco 2013).

5 Weigh-ins took place one day prior to each event.

6 FightMetric is the official statistics provider of the UFC. 
at distance, in the clinch, and on the ground. ${ }^{7}$ Table 1 contains complete descriptions of the variables employed in the present study.

Table 1. Variable descriptions.

\begin{tabular}{|c|c|}
\hline Variable Label & Description \\
\hline \multicolumn{2}{|l|}{ Dependent } \\
\hline FINISH & $\begin{array}{l}\text { Indicator variable equal to one if a fighter won by } \mathrm{KO} / \mathrm{TKO} \text { or submission, } \\
\text { and zero otherwise. }\end{array}$ \\
\hline KOTKO & $\begin{array}{l}\text { Indicator variable equal to one if a fighter won by } \mathrm{KO} / \mathrm{TKO} \text {, and zero } \\
\text { otherwise. }\end{array}$ \\
\hline SUBMISSION & $\begin{array}{l}\text { Indicator variable equal to one if a fighter won by submission, and zero } \\
\text { otherwise. }\end{array}$ \\
\hline STRIKERATE & Total strikes attempted per five minutes. \\
\hline PSTRIKERATE & $\begin{array}{l}\text { Total power strikes attempted per five minutes. FightMetric uses various } \\
\text { cues such as whether a strike is a kick, knee, elbow, or punch, how the strike } \\
\text { is thrown, the effect on the opponent, etc. to determine if a strike has power. }\end{array}$ \\
\hline DISTANCEPCT & $\begin{array}{l}\text { Percent of total fight time a fighter is standing and not touching the } \\
\text { opponent ( } 0-100 \text { scale). }\end{array}$ \\
\hline GROUNDPCT & Percent of total fight time a fighter is on the ground (0-100 scale). \\
\hline \multicolumn{2}{|l|}{ Independent } \\
\hline BONUS & $\begin{array}{l}\text { Monetary amount of any FOTN, KOTN, or SOTN awards for each event } \\
\text { (in thousands). }\end{array}$ \\
\hline REALBONUS & Inflation-adjusted BONUS using the Consumer Price Index. \\
\hline AGE & Age (in years). \\
\hline HEIGHT & Height (in inches). \\
\hline REACH & Reach (in inches). \\
\hline LEFTVSRIGHT & $\begin{array}{l}\text { Indicator variable equal to one if a fighter is left-handed (i.e., a southpaw) } \\
\text { fighting against a right-handed opponent, and zero otherwise. }\end{array}$ \\
\hline EXPER & The number of Zuffa bouts a fighter has in the FightMetric database. \\
\hline SNPROB & Standard normalization win probability of Sauer (2005). \\
\hline MAINEVENT & $\begin{array}{l}\text { Indicator variable equal to one if the bout headlined the event, } \\
\text { and zero otherwise. }\end{array}$ \\
\hline 5ROUNDS & $\begin{array}{l}\text { Indicator variable equal to one if the bout was scheduled for five rounds, } \\
\text { and zero otherwise. }\end{array}$ \\
\hline TITLE & $\begin{array}{l}\text { Indicator variable equal to one if the bout was a title fight, } \\
\text { and zero otherwise. }\end{array}$ \\
\hline PPV & $\begin{array}{l}\text { Indicator variable equal to one if the bout took place on a PPV event, and } \\
\text { zero otherwise. }\end{array}$ \\
\hline КОТКОРСТ & A fighter's prior percentage of wins by KO/TKO. \\
\hline SUBPCT & A fighter's prior percentage of wins by submission. \\
\hline WEIGHT & Weight class. Used for fixed effects. \\
\hline
\end{tabular}

7 Fighters are "at distance" when they are standing but separated, "in the clinch" when they are standing and touching each other, and "on the ground" when at least one of them is not standing. 


\subsection{Descriptive Statistics}

Descriptive statistics for the events, bouts, and bonus awards included in the sample are presented in Table 2. The full dataset includes over 250 events and more than 2500 bouts. When events contained bonus awards, the vast majority of the time one award of each type was allocated at the end of the night (93 percent for FOTN, 92 percent for KOTN, and 87 percent for SOTN). In the rare situations where no KOTN or SOTN was awarded, the event usually did not experience any qualifying $\mathrm{KO} / \mathrm{TKOs}$ or submissions.

Table 2. Event size and award statistics by promotion.

\begin{tabular}{|c|c|c|c|c|c|c|}
\hline & \multicolumn{2}{|c|}{ UFC } & \multicolumn{2}{|c|}{ WEC } & \multicolumn{2}{|c|}{ Total } \\
\hline \multicolumn{7}{|l|}{ All Events } \\
\hline Events & \multicolumn{2}{|c|}{227} & \multicolumn{2}{|c|}{29} & \multicolumn{2}{|c|}{256} \\
\hline Bouts & \multicolumn{2}{|c|}{2315} & \multicolumn{2}{|c|}{274} & \multicolumn{2}{|c|}{2589} \\
\hline Fighter-Bouts & \multicolumn{2}{|c|}{4630} & \multicolumn{2}{|c|}{548} & \multicolumn{2}{|c|}{5178} \\
\hline \multicolumn{7}{|c|}{ Events with Bonus Awards } \\
\hline Events & \multicolumn{2}{|c|}{192} & \multicolumn{2}{|c|}{29} & \multicolumn{2}{|c|}{221} \\
\hline Bouts & \multicolumn{2}{|c|}{2035} & \multicolumn{2}{|c|}{274} & \multicolumn{2}{|c|}{2309} \\
\hline Fighter-Bouts & \multicolumn{2}{|c|}{4070} & \multicolumn{2}{|c|}{548} & \multicolumn{2}{|c|}{4618} \\
\hline \multicolumn{7}{|c|}{ FOTN Awards per Event with Bonus } \\
\hline Zero & 3 & $2 \%$ & 1 & $3 \%$ & 4 & $2 \%$ \\
\hline One & 180 & $94 \%$ & 25 & $86 \%$ & 205 & $93 \%$ \\
\hline Two & 8 & $4 \%$ & 3 & $10 \%$ & 11 & $5 \%$ \\
\hline Three & $\underline{1}$ & $\underline{1 \%}$ & $\underline{0}$ & $\underline{0 \%}$ & $\underline{1}$ & $\underline{0 \%}$ \\
\hline Total & 192 & $100 \%$ & 29 & $100 \%$ & 221 & $100 \%$ \\
\hline \multicolumn{7}{|c|}{ KOTN Awards per Event with Bonus } \\
\hline Zero & 8 & $4 \%$ & 1 & $3 \%$ & 9 & $4 \%$ \\
\hline One & 176 & $92 \%$ & 28 & $97 \%$ & 204 & $92 \%$ \\
\hline Two & 7 & $4 \%$ & 0 & $0 \%$ & 7 & $3 \%$ \\
\hline Three & $\underline{1}$ & $\underline{1 \%}$ & $\underline{0}$ & $\underline{0 \%}$ & $\underline{1}$ & $\underline{0 \%}$ \\
\hline$\overline{\text { Total }}$ & $1 \overline{9} 2$ & $\overline{100 \%}$ & 29 & $\overline{100 \%}$ & $2 \overline{2} 1$ & $100 \%$ \\
\hline \multicolumn{7}{|c|}{ SOTN Awards per Event with Bonus } \\
\hline Zero & 19 & $10 \%$ & 2 & $7 \%$ & 21 & $10 \%$ \\
\hline One & 166 & $86 \%$ & 27 & $93 \%$ & 193 & $87 \%$ \\
\hline Two & $\underline{7}$ & $\underline{4 \%}$ & $\underline{0}$ & $\underline{0 \%}$ & $\underline{7}$ & $3 \%$ \\
\hline$\overline{\text { Total }}$ & 192 & $\overline{100 \%} \%$ & 29 & $\overline{100 \%} \%$ & 221 & $100 \%$ \\
\hline
\end{tabular}

Note: For all Zuffa-owned Ultimate Fighting Championship (UFC) and World Extreme Cage (WEC) bouts from 4 May 2001 through 1 February 2014.

The first 35 UFC events in the dataset did not have bonus awards. In total, 192 UFC events had bonus awards ranging in value from $\$ 25,000$ to $\$ 129,000$. For the WEC, all 29 events had bonus awards ranging in value from $\$ 7500$ to $\$ 10,000$, with one exception. ${ }^{8}$ Figure 1 presents the time trend of bonus awards showing their variation event-by-event and over time, as well as the more recent period with bonuses standardized at $\$ 50,000$.

8 The promotion's sole PPV event, WEC 48, had bonus awards of $\$ 65,000$. 


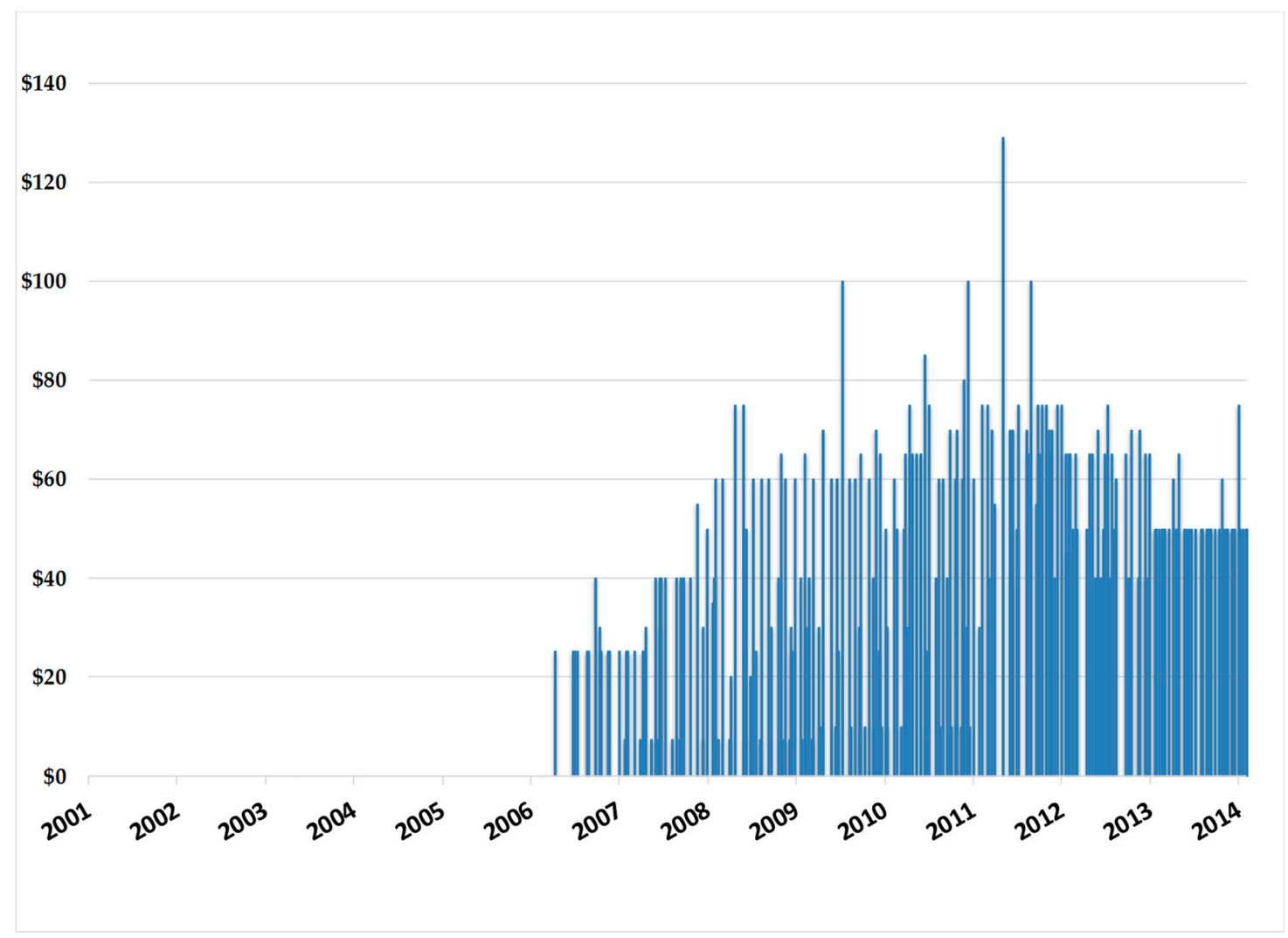

Figure 1. Fight night bonuses over time. Note: For all Zuffa-owned UFC and WEC bouts from 4 May 2001 through 1 February 2014. Data in thousands.

Table 3 presents summary statistics of the variables used in the analysis. The top panel contains potential performance variables of interest relating to fight finishes (FINISH, KOTKO, and SUBMISSION), action (STRIKERATE and PSTRIKERATE), and fight positioning (DISTANCEPCT and GROUNDPCT). The bottom panel contains bonuses and controls for fighter characteristics tracked by FightMetric (AGE, HEIGHT, REACH, and LEFTVSRIGHT), experience, and win probability; bout characteristics that may explain differences in performance variables such as whether the bout was a main event, title, or five-round fight; and an event characteristic for whether the event was on PPV. When regression analyses are performed, AGE, HEIGHT, REACH, LEFTVSRIGHT, and EXPER are the difference in values between the fighter in question and the opponent.

Table 3. Summary statistics.

\begin{tabular}{lccccc}
\hline Variables & Mean & S.D. & N & Min & Max \\
\hline Dependent & & & & & \\
FINISH & 0.29 & 0.45 & 5178 & 0 & 1 \\
KOTKO & 0.17 & 0.38 & 5178 & 0 & 1 \\
SUBMISSION & 0.11 & 0.32 & 5178 & 0 & 1 \\
STRIKERATE & 44.92 & 22.07 & 5178 & 0.0 & 416.7 \\
PSTRIKERATE & 22.01 & 13.52 & 5178 & 0.0 & 416.7 \\
DISTANCEPCT & 45.84 & 27.69 & 5178 & 1.0 & 100.0 \\
GROUNDPCT & 37.90 & 26.94 & 5178 & 0.0 & 97.2 \\
\hline
\end{tabular}


Table 3. Cont.

\begin{tabular}{lccccc}
\hline Variables & Mean & S.D. & N & Min & Max \\
\hline Independent & & & & & \\
BONUS & 42.35 & 25.20 & 5178 & 0 & 129 \\
REALBONUS & 45.09 & 26.58 & 5178 & 0 & 136 \\
AGE & 29.17 & 3.99 & 5120 & 18.5 & 47.9 \\
HEIGHT & 70.80 & 3.16 & 5174 & 61.0 & 83.0 \\
REACH & 72.71 & 3.65 & 4443 & 62.0 & 84.5 \\
LEFTVSRIGHT & 0.15 & 0.36 & 5062 & 0 & 1 \\
EXPER & 5.39 & 4.45 & 5178 & 1 & 24 \\
SNPROB & 50.00 & 18.88 & 4912 & 7.0 & 93.0 \\
MAINEVENT & 0.10 & 0.30 & 5178 & 0 & 1 \\
5ROUNDS & 0.08 & 0.27 & 5178 & 0 & 1 \\
TITLE & 0.07 & 0.25 & 5178 & 0 & 1 \\
PPV & 0.51 & 0.50 & 5178 & 0 & 1 \\
KOTKOPCT & 0.32 & 0.35 & 4161 & 0 & 1 \\
SUBPCT & 0.23 & 0.32 & 4161 & 0 & 1 \\
\hline
\end{tabular}

Note: For all Zuffa-owned UFC and WEC bouts from 4 May 2001 through 1 February 2014. Bout-level observations for each fighter. STRIKERATE, PSTRIKERATE, DISTANCEPCT, and GROUNDPCT means are weighted by total time. REALBONUS is the inflation-adjusted BONUS using the Consumer Price Index (CPI).

\section{Model}

The identification strategy in this paper exploits the variation of fight night bonus awards over time and across events. Two models were employed to explain fighter performance outcomes $(Y)$. The first directly examines the role of inflation-adjusted bonuses, REALBONUS, and is specified as:

$$
\begin{aligned}
& \gamma_{f b w t}=\beta_{0}+\gamma_{t}+\gamma_{w}+\beta_{1} \cdot R E A L B O N U S_{b w t}+\beta_{2} \cdot A G E_{f b w t}+\beta_{3} \cdot H E I G H T_{f b w t} \\
& +\beta_{4} \cdot R E A C H_{f b w t}+\beta_{5} \cdot L_{E F T V S R I G H T} \text { fbwt }+\beta_{6} \cdot \text { EXPER }_{f b w t} \\
& +\beta_{7} \cdot S N P R O B_{f b w t}+\beta_{8} \cdot M \text { AINEVENT } T_{b w t}+\beta_{9} \cdot 5 R O U N D S_{b w t} \\
& +\beta_{10} \cdot \text { TITLE }_{b w t}+\beta_{11} \cdot P P V_{b w t}+\varepsilon_{f b w t}
\end{aligned}
$$

where $f b w t$ denotes fighter $f$ in bout $b$ in weight class $w$ in time period $t . \lambda_{t}$ and $\gamma_{w}$ are fixed effects for 14 time periods from 2001 to 2014 and nine weight classes, respectively. The parameter of interest is $\beta_{1}$, the marginal effect of REALBONUS.

The second model includes an interaction term allowing the marginal effect of REALBONUS to vary by pre-fight characteristics KOTKOPCT or SUBPCT. It is specified as:

$$
\begin{gathered}
Y_{f b w t}=\beta_{0}+\gamma_{t}+\gamma_{w}+\beta_{1} \cdot R E A L B O N U S_{b w t}+\beta_{2} \cdot X_{f b w t} \\
+\beta_{3} \cdot R E A L B O N U S_{b w t} \cdot X_{f b w t}+\beta_{4} \cdot A G E_{f b w t}+\beta_{5} \cdot H E I G H T_{f b w t} \\
+\beta_{6} \cdot R E A C H_{f b w t}+\beta_{7} \cdot L E F T V S R I G H T_{f b w t}+\beta_{8} \cdot \text { EXPER }_{f b w t} \\
+\beta_{9} \cdot S N P R O B_{f b w t}+\beta_{10} \cdot M A I N E V E N T_{b w t}+\beta_{11} \cdot 5 R O U N D S_{b w t} \\
+\beta_{12} \cdot T_{I T L E} E_{b w t}+\beta_{13} \cdot P P V_{b w t}+\varepsilon_{f b w t}
\end{gathered}
$$

where $X$ is either KOTKOPCT or SUBPCT depending on the performance outcome examined. The equation of interest is the marginal effect of REALBONUS $\left(\beta_{1}+\beta_{3} \cdot X\right)$, which will be examined at the 10th, 25th, 50th, 75th, and 90th percentiles of $X$.

Equations (1) and (2) were estimated using logit and OLS regressions for binary and continuous performance outcomes, respectively. Standard errors were cluster-corrected at the event level as some performance outcome error terms were correlated across fighter-bout observations. For example, if one fighter's FINISH indicator is " 1 ," the opponent's will be " 0 ," leading to a negative correlation of error terms within bouts. 


\section{Empirical Results}

Table 4 presents results for five performance outcomes relating to finishing the fight and action. Results suggest that older fighters earn fewer finishes, due to reduced wins by $\mathrm{KO} / \mathrm{TKO}$, and tend to have lower overall and power striking rates. Fighters with a longer reach and southpaw's fighting orthodox fighters appear to earn more finishes, again through $\mathrm{KO} / \mathrm{TKO}$. More experienced fighters saw an increase in submission finishes while fighters with higher betting odds had significant increases in all performance outcomes. However, changes in REALBONUS did not have a significant impact on fight finishes or striking activity.

Table 4. Effect of fight night bonuses on performance variables of interest.

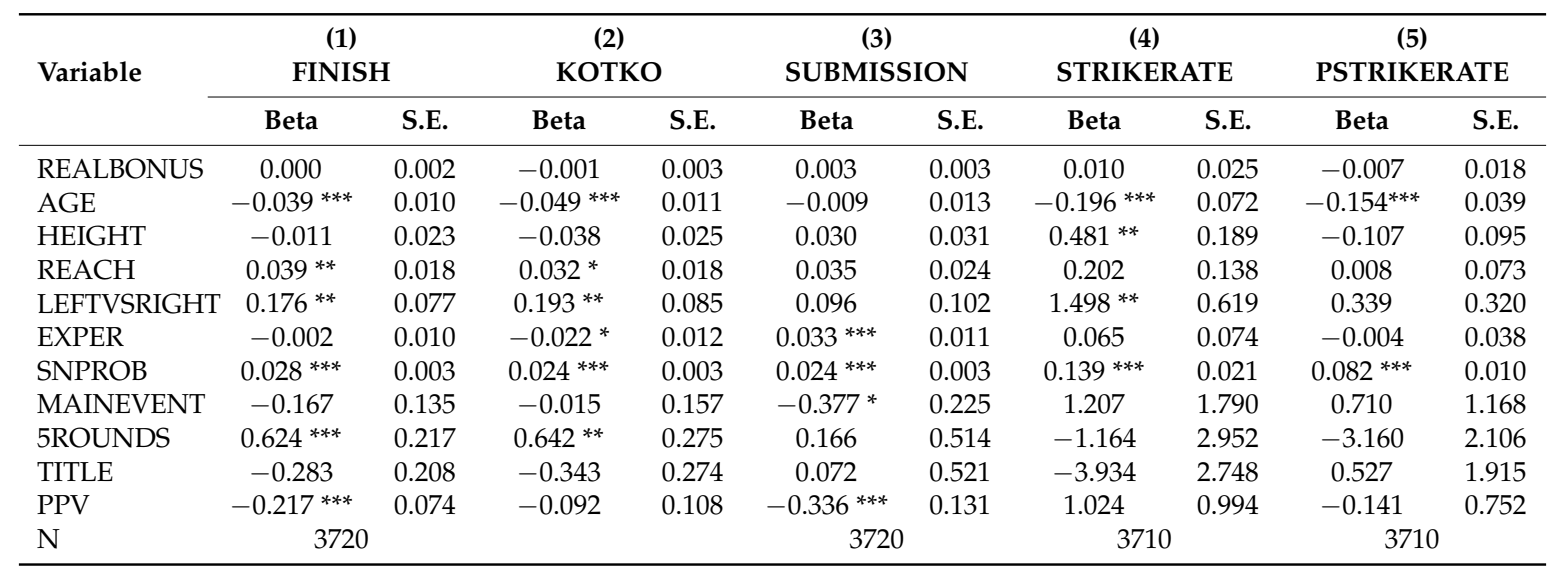

Note: Regressions 1 to 3 utilize a logit model while regressions 4 to 5 utilize OLS and are weighted by total time. AGE, HEIGHT, REACH, LEFTVSRIGHT, and EXPER are the difference in values between the fighter in question and the opponent. All regressions contain year and weight class fixed effects. Standard errors were cluster-corrected at the event level. $* * * * *$, and $*$ indicate significance at the 1,5 , and 10 percent levels, respectively.

It is possible that certain types of fighters may have different motivations when bonus levels change. Those with a history of knockout finishes may devote more effort towards obtaining a $\mathrm{KO} / \mathrm{TKO}$, throwing heavy strikes, or remaining in the best position to win a KOTN award. Those with a history of submission finishes may devote more effort towards obtaining a submission or being in the best position to win a SOTN award. To that end, the next two figures show the distribution of fight positions from which fighters won KOTN awards relative to all other $\mathrm{KO} / \mathrm{TKO}$ finishes (Figure 2) and SOTN awards relative to all other submission finishes (Figure 3). Figure 2 supports the notion that $\mathrm{KO} / \mathrm{TKO}$ from the distance position (i.e., the big knockout blow) are more likely to be perceived as higher quality by promotion executives than "ground and pound" finishes on the canvas. If fighters are aware of this, those attempting to win KOTN may be incentivized to try to keep the fight at distance.

Figure 3 suggests that submissions are different. A particular fight position doesn't appear more likely to win SOTN, but the vast majority of submissions (87 percent) took place on the ground. A fighter incentivized to win SOTN will surely take a submission wherever he or she can get it but may apply extra effort to take and keep the fight on the ground knowing most submissions occur from that position.

Table 5 presents results when interactions were included to control for potential differences in fighter types. The first four columns show that fighters with a greater history (i.e., percentage) of $\mathrm{KO} / \mathrm{TKO}$ finishes tended to be more likely to earn a $\mathrm{KO} / \mathrm{TKO}$ finish in their current bout, had higher overall and power striking rates, and tended to spend more fight time at distance. The final two columns suggest that those with a greater history of submission finishes were more likely to achieve a submission in their current bout and tended to spend more fight time on the ground, where the majority of submissions occur. The interaction of REALBONUS with either KOTKOPCT or SUBPCT allows the marginal effect of bonus levels to vary by a fighter's prior history with KO/TKOs or submissions. These marginal effects are examined at the 10th, 25th, 50th, 75th, and 90th percentiles in 
Figure 4 and are presented with 95 percent confidence bands. All marginal effects of REALBONUS were insignificant, suggesting that while fighters of various types may strike and position themselves differently with different likelihoods of obtaining $\mathrm{KO} / \mathrm{TKO}$ or submission finishes, their performances do not appear to be meaningfully influenced by the level of fight night bonuses.

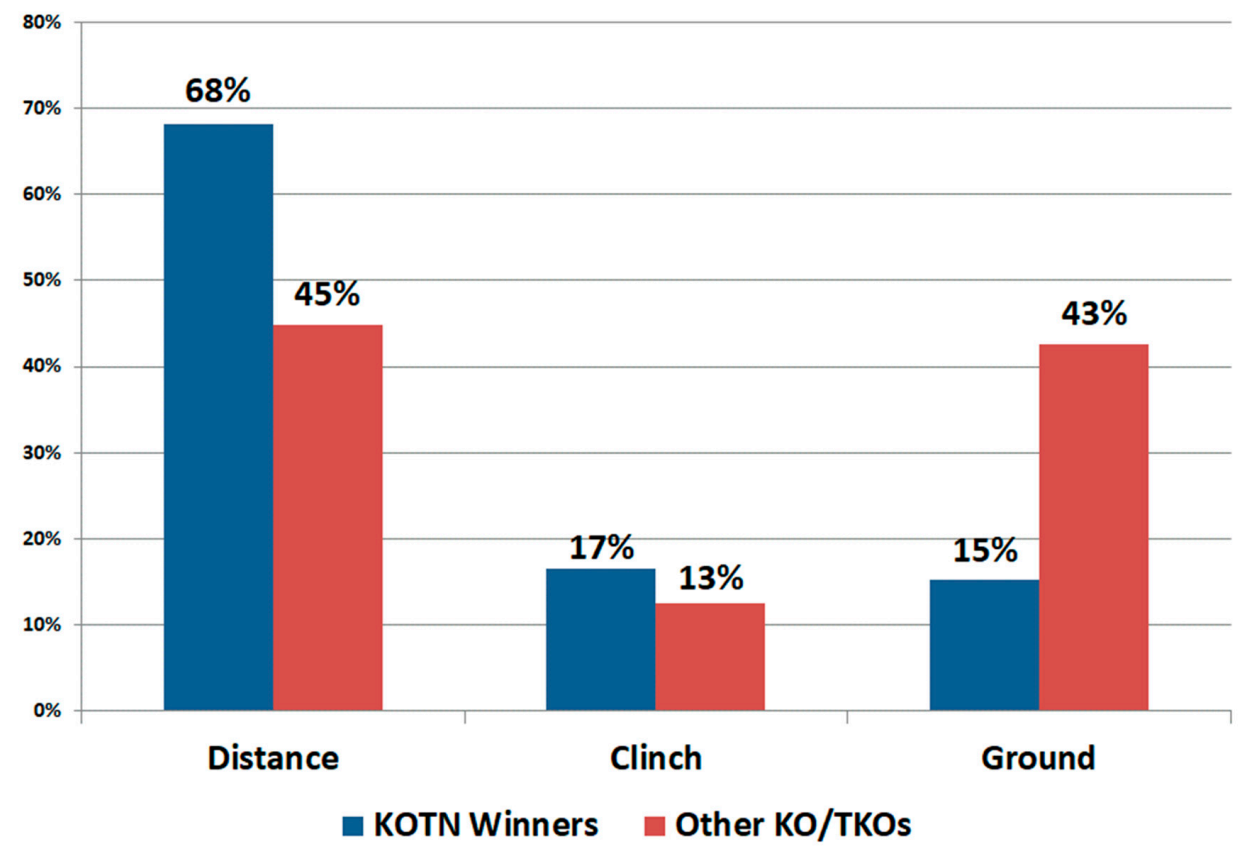

Figure 2. Fight ending positions for Knockout of the Night (KOTN) finishes and other KO/TKOs. Note: For all Zuffa-owned UFC and WEC bouts from 4 May 2001 through 1 February 2014.

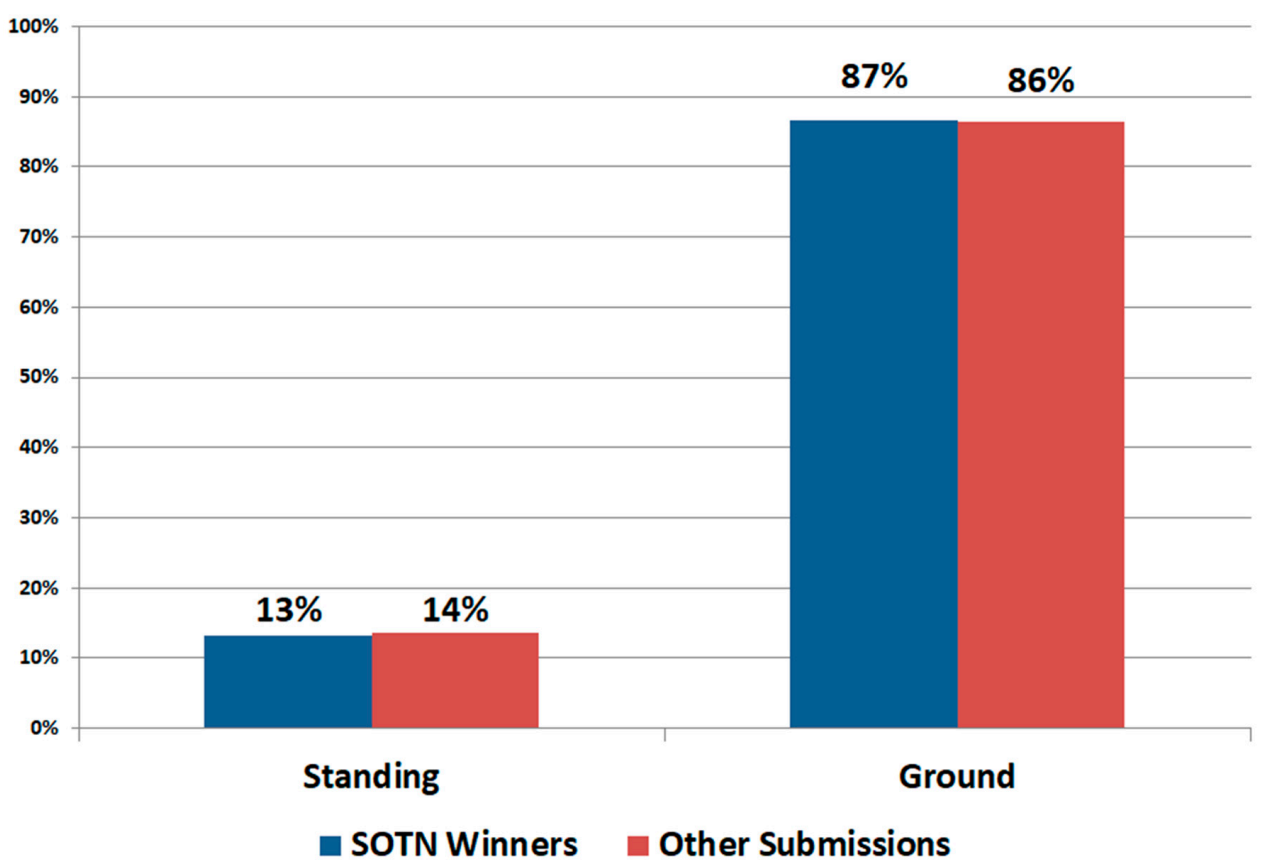

Figure 3. Fight ending positions for Submission of the Night (SOTN) finishes and other submissions. Note: For all Zuffa-owned UFC and WEC bouts from 4 May 2001 through 1 February 2014. Standing position is when fighters are either at distance or in the clinch. 
Table 5. Effect of fight night bonuses with $\mathrm{KO} / \mathrm{TKO}$ or submission interaction effects.

\begin{tabular}{|c|c|c|c|c|c|c|c|c|c|c|c|c|}
\hline \multirow[t]{2}{*}{ Variable } & \multicolumn{2}{|c|}{$\begin{array}{c}\text { (1) } \\
\text { KOTKO }\end{array}$} & \multicolumn{2}{|c|}{$\begin{array}{c}(2) \\
\text { STRIKERATE }\end{array}$} & \multicolumn{2}{|c|}{$\begin{array}{c}\text { (3) } \\
\text { PSTRIKERATE }\end{array}$} & \multicolumn{2}{|c|}{$\begin{array}{c}(4) \\
\text { DISTANCEPCT }\end{array}$} & \multicolumn{2}{|c|}{$\begin{array}{c}\text { (5) } \\
\text { SUBMISSION }\end{array}$} & \multicolumn{2}{|c|}{$\begin{array}{c}\text { (6) } \\
\text { GROUNDPCT }\end{array}$} \\
\hline & Beta & S.E. & Beta & S.E. & Beta & S.E. & Beta & S.E. & Beta & S.E. & Beta & S.E. \\
\hline REALBONUS & 0.001 & 0.003 & 0.022 & 0.026 & -0.015 & 0.018 & -0.023 & 0.048 & 0.002 & 0.004 & 0.055 & 0.051 \\
\hline КОTКОРСТ & $0.829^{* * *}$ & 0.308 & $4.535^{* *}$ & 2.183 & $2.701^{* *}$ & 1.329 & $6.650 *$ & 3.396 & & & & \\
\hline REALBONUS $\times$ KOTKOPCT & -0.004 & 0.005 & $-0.076^{* *}$ & 0.038 & 0.006 & 0.023 & 0.018 & 0.061 & & & & \\
\hline SUBPCT & & & & & & & & & $1.240^{* * *}$ & 0.337 & $7.794^{* *}$ & 3.628 \\
\hline REALBONUS $\times$ SUBPCT & & & & & & & & & 0.004 & 0.006 & -0.002 & 0.069 \\
\hline AGE & $-0.054^{* * *}$ & 0.013 & $-0.213^{* * *}$ & 0.078 & $-0.158^{* * *}$ & 0.043 & -0.060 * & 0.036 & -0.013 & 0.013 & 0.056 & 0.037 \\
\hline HEIGHT & $-0.051 *$ & 0.028 & $0.435^{* *}$ & 0.206 & -0.144 & 0.105 & -0.024 & 0.071 & 0.003 & 0.034 & 0.005 & 0.075 \\
\hline REACH & $0.039 * *$ & 0.020 & 0.236 & 0.150 & 0.029 & 0.083 & -0.054 & 0.054 & 0.041 & 0.025 & -0.001 & 0.061 \\
\hline LEFTVSRIGHT & $0.177^{* *}$ & 0.088 & $1.656^{* *}$ & 0.660 & 0.353 & 0.354 & -0.151 & 0.184 & 0.157 & 0.111 & 0.258 & 0.184 \\
\hline EXPER & -0.018 & 0.012 & 0.038 & 0.078 & -0.018 & 0.040 & -0.003 & 0.033 & $0.040^{* * *}$ & 0.013 & 0.000 & 0.033 \\
\hline SNPROB & $0.023^{* * *}$ & 0.003 & $0.133^{* * *}$ & 0.023 & $0.078^{* * *}$ & 0.011 & $-0.015^{*}$ & 0.008 & $0.027^{* * *}$ & 0.004 & 0.010 & 0.009 \\
\hline MAINEVENT & -0.014 & 0.160 & 1.124 & 1.918 & 0.445 & 1.236 & $7.621^{* *}$ & 3.028 & -0.298 & 0.237 & $-9.033^{* * *}$ & 2.813 \\
\hline 5ROUNDS & $0.630^{* *}$ & 0.279 & -1.323 & 2.947 & -3.349 & 2.086 & -3.146 & 6.160 & 0.171 & 0.506 & 5.541 & 4.508 \\
\hline TITLE & -0.361 & 0.280 & -4.408 & 2.680 & 0.173 & 1.831 & 5.566 & 6.033 & 0.097 & 0.516 & -4.886 & 4.259 \\
\hline PPV & -0.083 & 0.108 & 1.157 & 1.014 & -0.125 & 0.743 & 2.535 & 1.839 & $-0.368^{* * *}$ & 0.135 & -1.511 & 1.775 \\
\hline $\mathrm{N}$ & \multicolumn{2}{|c|}{3313} & \multicolumn{2}{|c|}{3313} & \multicolumn{2}{|c|}{3313} & \multicolumn{2}{|c|}{3313} & \multicolumn{2}{|c|}{3305} & \multicolumn{2}{|c|}{3313} \\
\hline
\end{tabular}

Note: Regressions 1 and 5 utilize a logit model while regressions 2 to 4 and 6 utilize OLS and are weighted by total time. AGE, HEIGHT, REACH, LEFTVSRIGHT, and EXPER are the difference in values between the fighter in question and the opponent. All regressions contain year and weight class fixed effects. Standard errors were cluster-corrected at the event level.

$* * * * *$ and * indicate significance at the 1,5 , and 10 percent levels, respectively. 
КОТКО

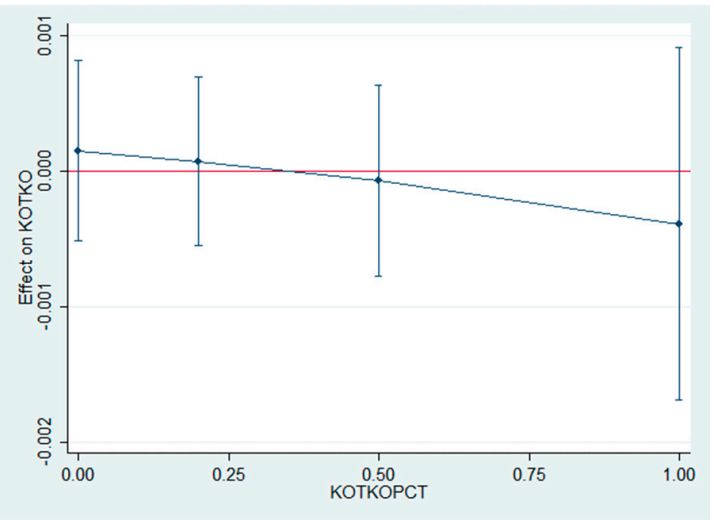

PSTRIKERATE

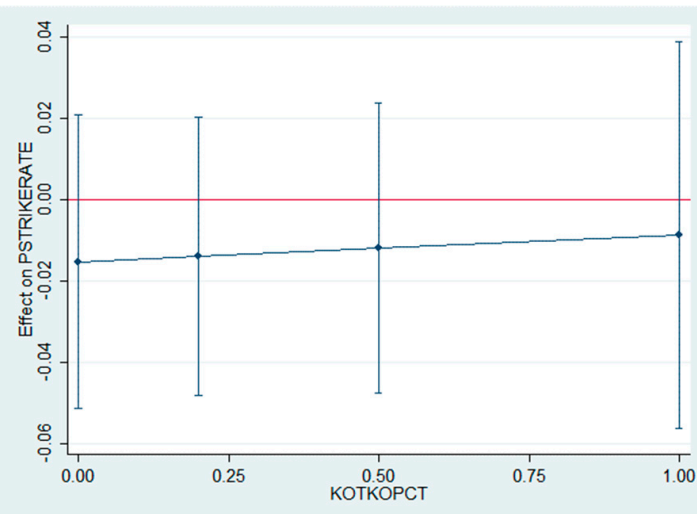

SUBMISSION

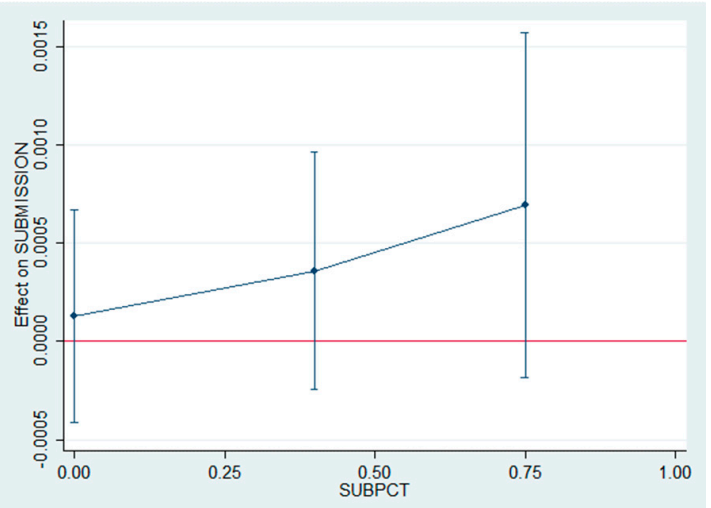

STRIKERATE

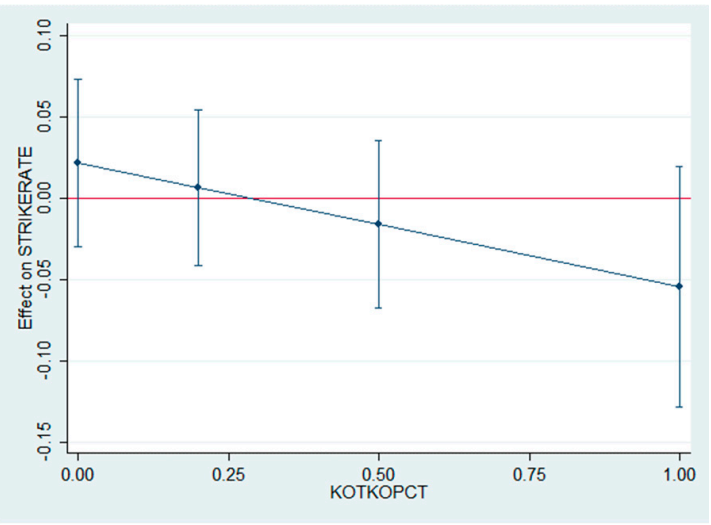

DISTANCEPCT

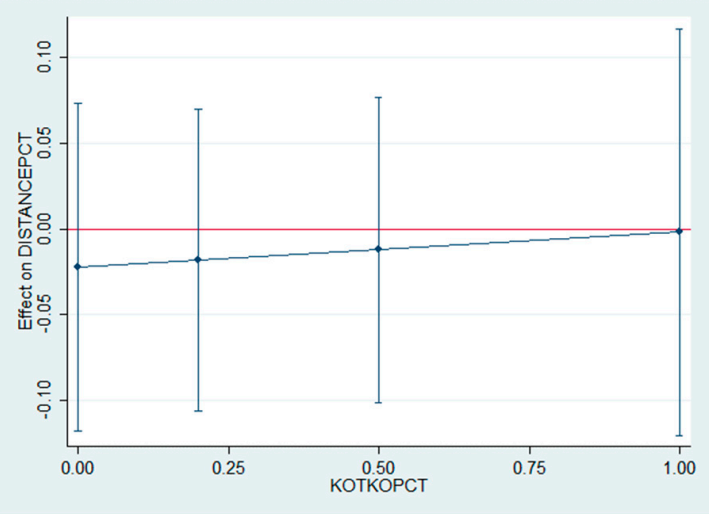

GROUNDPCT

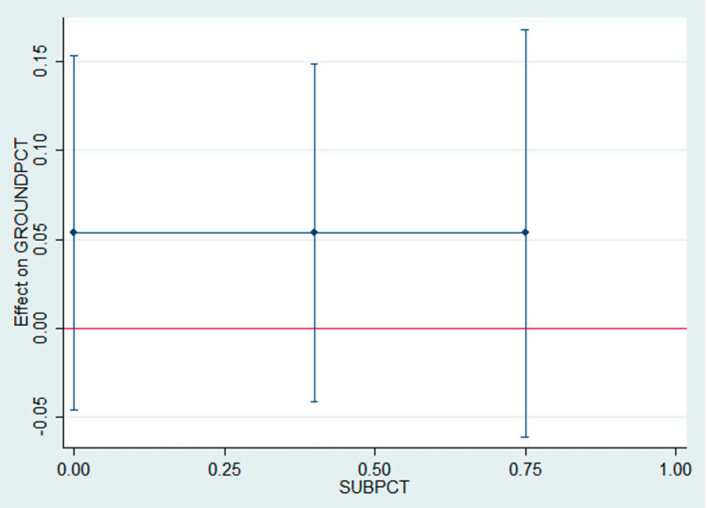

Figure 4. Marginal effects of REALBONUS with KOTKOPCT or SUBPCT interactions. Note: For all Zuffa-owned UFC and WEC bouts from 4 May 2001 through 1 February 2014. The 10th and 25th percentiles of KOTKOPCT and the 10th, 25th, and 50th percentiles of SUBPCT were identical at zero percent.

\section{Discussion}

Fight night bonuses in MMA are not unique to Zuffa (under the UFC and WEC promotions). Other promotions have utilized KOTN, SOTN, and FOTN bonuses or variants such as a special bonus for specific finishing moves, a bonus for every finish, or bonuses for making an "impression" on the CEO. To my knowledge, this is the first study to examine the incentive effects of particular MMA bonuses on fighter performance.

Tournament theory predicts that more effort will be put into production when there is a large difference between winning and losing payouts. Zuffa fighter payouts are known to take a variety of different potential forms, per court documents (Le et al. 2018). All fighters receive their contractual 
show money. Most fighters, but not all, earn a win money bonus for winning their bout, and it is often an amount equal to their show money. Some fighters receive contractual side-letter compensation, some earn PPV points, and "locker room" bonuses are sometimes paid to fighters at the discretion of UFC management. The latter three forms of compensation are private information between fighters and the UFC. However, show and win money payments are occasionally disclosed by the state or tribal athletic commissions regulating the event.

Since every fighter is, at minimum, guaranteed their show money, such data were collected from the Nevada State Athletic Commission for UFC events promoted in the state from 2001 to 2014 as well as 49 events in other states from public media reports. In all, show money data were collected for 2860 of the fighter-bouts in the sample period (55.2 percent). While an inherently incomplete picture of fighter compensation, Figure 5 shows the distribution of show money as one might expect in the tournament over time to become champion. Eighty-one percent of fighter appearances earned $\$ 25,000$ or less in guaranteed show money while 3.1 percent, generally champions or otherwise popular fighters, earned $\$ 150,000$ or more. The figure also allows for a visual distributional comparison of show money relative to fight night bonus amounts. For 76.1 percent of fighter appearances, a fight night bonus was worth more than their guaranteed show money and, on average, those bonuses were 269 percent larger than show money. Additionally, fighters can potentially win KOTN or SOTN in conjunction with FOTN to further increase their monetary compensation. ${ }^{9}$ Hence, relative to contracted show money compensation, Zuffa fight night bonuses should theoretically serve as a substantial monetary inducement to influence fighter behavior inside the cage.

While fighters are aware of bonus sizes before an event and have even lobbied UFC President Dana White to increase them (Marrocco 2013), the evidence in the present study does not suggest that MMA fighters' in-cage performances are affected by such monetary incentives. All findings suggest that fight finishes, striking activity, and fight positioning are unaffected by the size of fight night bonus awards.

While it is beyond the scope of this paper to perform an in-depth analysis on the mechanisms contributing to such a benign effect, fighter perceptions and the possibility of conflicting incentives may offer plausible explanations. First, marginal changes in effort levels from what they otherwise would have been without fight night bonuses may be perceived as only trivially affecting one's probability of finishing the opponent or generating excitement. When fighters are locked in the cage, not only are their livelihoods be on the line, but also their health and, potentially, their lives. Fighters may thus already be sufficiently incentivized to exert effort, not only to win the fight, but to keep from absorbing too much physical damage in the process.

Second, the marginal cost of additional effort may be substantial when opportunity costs are considered. As supported earlier by Figure 5, the compensation structure is heavily skewed in favor of champions, former champions, and those near the top of the rankings, not only in terms of salaries but also in-cage and out-of-cage endorsements. If marginal effort towards obtaining a bonus is detrimental to the probability of winning (e.g., hunting for a knockout), these non-linear future earnings would be further at risk.; and more immediately, a fighter's win bonus would be at risk. While win bonuses are often identical to a fighter's show money and therefore smaller than fight night bonuses, they are a guaranteed payment to all victorious fighters who have them in their promotional contract.

Third, the structure of fighter contracts may be another explanatory factor behind the findings of this paper. As a private company, the terms of Zuffa's fighter contracts were not public knowledge until a 2013 legal dispute led to disclosure of the promotion's standard contract. ${ }^{10}$ Examination of its terms reveals another potential incentive for devoting effort towards winning the bout instead of obtaining a bonus. Fighters typically sign multi-fight, exclusive contracts with the UFC, but they can

9 For example, Pat Barry won $\$ 120,000$ in bonuses (KOTN and FOTN) at UFC 104 while his contracted show and win money were $\$ 7000$ each.

10 In December 2012, Bellator's former lightweight champion, Eddie Alvarez, signed with the UFC. Bellator exercised its right of first refusal and sued Alvarez to enforce its contractual matching rights. 
be released any time they are "not declared the winner" of a bout (Snowden 2013). Thus, not only does a win progress a fighter up the rankings and towards higher future non-linear rewards, it also ensures the maintenance of their roster spot in the top MMA promotion in the world.


Figure 5. Distribution of fighter show money and fight night bonuses. Note: UFC and WEC combined. Data in thousands of dollars.

In Berri et al. (2015) study of salary determination in the presence of fixed revenues, they found evidence that players in the Big 4 sports leagues were substantially overpaid by the logic of the traditional model of wage determination. They noted that owners were unlikely to systematically make errors of such magnitudes and argued that salaries reflect a combination of expected performance and bargaining power. With respect to the present study, if the sole purpose of fight night bonuses were to ex ante incentivize fighter performance, it seems unlikely UFC management would continue such a practice with a benign effect, especially considering that the next-largest competitor, Bellator MMA, does not utilize bonuses. 
One possibility is that fight night bonuses serve as an additional form of compensation via lottery and Zuffa's fighters exhibit risk seeking behavior. Optimism bias can lead to the overweighting of small probabilities and give rise to risk seeking (Kahneman and Tversky 1982). Bleichrodt et al. (2018) studied field hockey players and found that professional players were more optimistic and over weighted their probability of winning relative to a recreational group. McCann (2006) documented potential optimism bias in incentive-laden athlete contract negotiations. In the UFC, an anecdote is suggestive that fighters may prefer a portion of their compensation via lottery. In 2013, following a large amount of complaints about fighter pay, UFC President Dana White suggested the promotion could raise the pay of fighters on the lower end of the pay scale and eliminate fight night and locker room bonuses. Not long after, White stated, "I got a lot of feedback. The fighters want the (fight-night) bonuses and they want the discretionary bonuses to stay the same. So that's that" (Erickson 2013). Thus, while fight night bonuses do not appear to influence in-cage fighter performance, they may serve as a preferred method of additional compensation for fighters with optimism bias regarding their chances of winning such awards.

\section{Conclusions}

Fight night bonuses can be a powerful means to supplement living and training expenses, especially for a UFC fighter earning $\$ 8000$ to show and $\$ 8000$ to win by the end of the sample period. Yet even with these seemingly strong incentives and bonuses on average 269 percent larger than guaranteed show money pay, I find no evidence to suggest that fighters are meaningfully influenced by bonus levels within the observed range. Fighter perceptions regarding marginal changes in effort and conflicting incentives to move up in rankings, obtain a win bonus, and maintain one's Zuffa roster spot may offer plausible explanations. Fight night bonuses instead appear to serve as a lottery compensation mechanism to ex post reward performances consistent with an MMA promotion's desires rather than ex ante incentivize such performances and may be a preferred method of compensation for fighters with optimism bias.

Acknowledgments: I am grateful for helpful comments and suggestions from Rami Genauer, Michael Gift, seminar participants at Pepperdine University, conference participants at the Western Economic Association, and excellent research assistance from Willis Clow and Dai Shiheng. I would like to thank Rami Genauer and FightMetric LLC for providing the fighter performance data. Any remaining errors are my own.

Conflicts of Interest: The author declares no conflict of interest.

\section{References}

Becker, Brian, and Mark Huselid. 1992. The incentive effects of tournament compensation systems. Administrative Science Quarterly 37: 336-50. [CrossRef]

Berri, David, Michael Leeds, and Peter von Allmen. 2015. Salary determination in the presence of fixed revenues. International Journal of Sport Finance 10: 5-25.

Bieler, Des. 2016. New York Becomes Final State to Legalize MMA Events. Washingtonpost.com. Available online: https:/ / www.washingtonpost.com/news/early-lead/wp/2016/03/22/new-york-becomes-finalstate-to-legalize-mma-events (accessed on 12 February 2018).

Bleichrodt, Han, Olivier L'Haridon, and David Van Ass. 2018. The risk attitudes of professional athletes: Optimism and success are related. Decision 5: 95-118. [CrossRef]

Collier, Trevor, Andrew L. Johnson, and John Ruggiero. 2012. Aggression in mixed martial arts: An analysis of the likelihood of winning a decision. In Violence and Aggression in Sporting Contests: Economics, History, and Policy. Edited by R. Todd Jewell. New York: Springer, pp. 97-109.

Ehrenberg, Ronald, and Michael Bognanno. 1990a. Do tournaments have incentive effects? Journal of Political Economy 98: 1307-24. [CrossRef]

Ehrenberg, Ronald, and Michael Bognanno. 1990b. The incentive effects of tournaments revisited: Evidence from the European PGA tour. Industrial \& Labor Relations Review 43: 74S-88S. 
Erickson, Matt. 2013. Dana White Makes It Official: UFC Fight-Night Bonuses Staying. Mmajunkie.com. Available online: https:/ / mmajunkie.com/2013/07/ dana-white-makes-it-official-ufc-fight-night-bonuses-staying (accessed on 12 May 2018).

Genauer, Rami. 2013. Interviewed by Paul Gift, Los Angeles, CA, January.

Gift, Paul. 2018. Moving the Needle in MMA: On the Marginal Revenue Product of UFC Fighters. Manuscript submitted for publication.

Kahneman, Daniel, and Amos Tversky. 1982. The psychology of preferences. Scientific American 246: 160-73. [CrossRef]

Lazear, Edward, and Paul Oyer. 2012. Personnel economics. In The Handbook of Organizational Economics. Edited by Robert Gibbons and John Roberts. Princeton: Princeton University Press, pp. 479-519.

Le, Cung, Nathan Quarry, Jon Fitch, Brandon Vera, Luis Javier Vazquez, Kyle Kingsbury, and Zuffa, LLC. 2018. Case No. 2:15-cv-01045-RFB-PAL. Zuffa, LLC's Opposition to Plaintiffs' Motion for Class Certification. ECF No. 540, Exhibit 92 (D. Nev. April 6, 2018) .

Lynch, James, and Jeffrey Zax. 2000. The rewards to running. Journal of Sports Economics 1: 323-40. [CrossRef]

Maloney, Michael, and Robert McCormick. 2000. The response of workers to wages in tournaments: Evidence from foot races. Journal of Sports Economics 1: 99-123. [CrossRef]

Marrocco, Steven. 2013. Bryan Caraway Haggles for Bigger Fight-Night Bonuses at UFC 159. Mmajunkie.com. Available online: http:/ / mmajunkie.com/2013/04/bryan-caraway-haggles-for-bigger-fight-night-bonusesat-ufc-159 (accessed on 15 May 2018).

McCann, Michael. 2006. It's not about the money: The role of preferences, cognitive biases and heuristics among professional athletes. Brooklyn Law Review 71: 1459-528.

MMA Junkie Staff. 2013. All UFC Fight-Night Bonuses Now Capped at \$50,000. Mmajunkie.com. Available online: http:/ / mmajunkie.com/2013/03/all-ufc-fight-night-bonuses-now-capped-at-50000 (accessed on 15 May 2018).

Reams, Lamar, and Stephen Shapiro. 2017. Who's the main attraction? Star power as a determinant of Ultimate Fighting Championship pay-per-view demand. European Sport Management Quarterly 17: 132-51. [CrossRef]

Sauer, Raymond D. 2005. The state of research on markets for sports betting and suggested future directions. Journal of Economics and Finance 29: 416-26. [CrossRef]

Snowden, Jonathan. 2013. The Business of Fighting: A Look inside the UFC's Top-Secret Fighter Contract. Bleacherreport.com. Available online: https://bleacherreport.com/articles/1516575-the-business-offighting-a-look-inside-the-ufcs-top-secret-fighter-contract (accessed on 15 May 2018).

Tainsky, Scott, Steven Salaga, and Carla Almeida Santos. 2012. Estimating attendance for the Ultimate Fighting Championship: A demand theory approach. International Journal of Sport Management and Marketing 11: 206-24. [CrossRef]

Tainsky, Scott, Steven Salaga, and Carla Almeida Santos. 2013. Determinants of pay-per-view broadcast viewership in sports: The case of the Ultimate Fighting Championship. Journal of Sport Management 27: 43-58. [CrossRef]

Tenorio, Rafael. 2000. The economics of professional boxing contracts. Journal of Sports Economics 1: 363-84. [CrossRef]

UFC. 2014. UFC Statement on Fight Night Bonuses. Ufc.com. Available online: http:/ /www.ufc.com/news/UFCStatement-on-Fight-Night-Bonuses (accessed on 19 May 2018).

UFC. 2019. About UFC. Ufc.com. Available online: https:/ / www.ufc.com/about (accessed on 9 January 2019).

U.S. House of Representatives Committee on Energy and Commerce. 2017. Perspectives on Mixed Martial Arts: Background Memo. House.gov. Available online: https:/ / docs.house.gov/meetings/IF/IF17/20171109/ 106604/HHRG-115-IF17-20171109-SD003.pdf (accessed on 15 December 2017).

Watanabe, Nicholas. 2012. Demand for pay-per-view consumption of Ultimate Fighting Championship events. International Journal of Sport Management and Marketing 11: 225-38. [CrossRef]

Watanabe, Nicholas. 2015. Sources of direct demand: An examination of demand for the Ultimate Fighting Championship. International Journal of Sport Finance 10: 26-41.

(C) 2019 by the author. Licensee MDPI, Basel, Switzerland. This article is an open access article distributed under the terms and conditions of the Creative Commons Attribution (CC BY) license (http:/ / creativecommons.org/licenses/by/4.0/). 